septic and the wound taking some time to heal. As the hernial sac contained a mass of omentum, is it possible that this immediate improvement is caused by improved pancreatic circulation? Vasodilatation follows the administration of nicotinamide, as shown by flushing of the face, etc., and it is suggested that apart from the role of nicotinic acid in carbohydrate metabolism the beneficial effects of this drug in diabetes mellitus may partially be due to improved pancreatic circulation, and that this effect will vary with the dosage.

The patient is now in good health and has lost $11 \mathrm{lb} .(5 \mathrm{~kg}$.) in weight. He was a heavy beer-drinker prior to his admission, but he now drinks only a pint a day, and this may be a contributory factor in maintaining the improvement. I would be glad to hear your readers' views on the above case.-I am, etc.,

$$
\text { London, S.E.18. }
$$

S. Karani.

\section{Leukanaemia and Myelosclerosis}

SIR,- - I wish to enter a plea for the retention of the term "leukanaemia" in regard to cases of what is now termed leucoerythroblastic anaemia, with clinical or post-mortem evidence that a greatly damaged haemopoietic activity of the bone marrow has been supplemented by extramedullary haemopoiesis in the spleen an 2 probably liver ("megakaryocytic" splenomegaly and megakaryocytic hepatomegaly) and possibly in lymph glands. It will, however, be convenient to exclude those cases in which the failure of medullary haemopoiesis is due to carcinomatous infiltration or other neoplastic destruction of the bone marrow. The term "leukanaemia" would then be restricted to cases in which the bone-marrow failure is due to myelophthisis or fibrotic change (myelofibrosis, if this hybrid name is permissible) or to any kind of "myelosclerosis" in which the bone marrow is gradually destroyed or replaced by non-neoplastic endosteal osteoid or osseous formation. The term "myeloosteosclerosis" would distinguish such cases of bony myelosclerosis from " myelofibrosis."

A typical example of "leukanaemia," in the sense in which 1 propose to retain the term, was that which I described in 1904 under the heading "A Case of Leukanaemia with Great Hyperplasia of the Spleen and Prevertebral Haemolymph Glands and with Increase of Connective Tissue in the Bone Marrow" (British Medical Journal, 1904, 1, 1416, and Trans. path. Soc. Lond., 1904, 55, 288). The patient was a man aged 58 years admitted to hospital suffering from great anaemia, progressive weakness, anorexia, and tinnitus. These symptoms had developed during the last twelve months ; in fact, he had apparently been able to insure his life about one year before admission. He had lived in England since 1865 and had never had malaria or been out of Europe. Together with the leuco-erythroblastic anaemia there was great enlargement of the spleen and liver. At the necropsy the marrow of the shaft of the left humerus was carefully examined and found to have undergone transformation into a red substance of unusually firm consistence. This myelofibrosis was confirmed by microscopical examination. In sections of the spleen, liver, and kidneys there was absence of any reaction for free iron such as is found in pernicious anaemia. I concluded : "It is very tempting to suggest that the spleen (haemal gland) and the prevertebral haemolymph glands were actively engaged in supplementing the erythrocyte-forming functions of the diseased bone marrow." I alluded also to what French authors (as Vaquez and Aubertin) termed "anémie splénique myéloide." In a later paper (Med. Pr., 1928, 176, 174) I recorded another report, by Sir J. C. G. Ledingham, who kindly made a microscopical examination of the organs from my case after the one which I had reported. He drew attention to the peculiar type of myeloid transformation in the liver. "There were," he said, " numerous areas of veritable marrow, with extraordinary numbers of megakaryocytes, which occasionally showed mitosis. Some of the megakaryocytes were so large that they would not possibly have passed through the fine interacinous capillaries."

I borrowed the term "leukanaemia" from W. von Leube and from Arneth's haematological account of von Leube's case (Dtsch. Arch. klin. Med., 1901, 69, 331) and H. Luce's paper (Ibid., 1903, 77, 215), though my case was not exactly similar. I suppose now that my case must be classified among the cases of myelofibrosis of uncertain aetiology, with resulting sympto- matic leuco-erythroblastic anaemia. G. Carpenter and C. M. Flory (Arch. intern. Med., 1941, 67, 489) have headed a recent paper : "Chronic Non-leukaemic Myelosis: Report of a Case with Megakaryocytic Myeloid Splenomegaly, Leuco-erythroblastic Anaemia, Generalized Osteosclerosis, and Myelofibrosis.' As explained by L. A. Erf and P. A. Herbert (Ann. intern. Med. $1944,21,863$ ), myelofibrosis is not of course synonymous with aplastic anaemia. The bone marrow in the former is fibrotic and in the latter it is fatty. Extramedullary haemopoiesis exists in the former but not in the latter.

An important clinical point is that in "leukanaemia," as I propose to limit the term, splenectomy is, as has been often pointed out, absolutely contraindicated, because the enlarged spleen (part of the conservative mechanism of extramedullary haemopoiesis) is helping to keep the patient alive.

Incidentally, I should like to know whether the condition of "polyostotic focal fibrous dysplasia" (in which I would include cases of "Albright's disease") ever leads to a condition of leuco-erythroblastic anaemia, in fact, to leukanaemia, in the restricted sense of the term which I advocate. Another question: Can there be gelatinous degeneration of bone marrow, such as is occasionally met with at post-mortem examinations, which is not merely a paulo-ante-mortem phenomenon but may allow the patient to live long enough to develop a resulting condition of myelofibrosis?-I am. etc.,

London, W.1.

F. Parkes Weber.

\section{Pelvic Sympathectomy}

SIR,-I was interested to read that Prof. J. P. Greenhill (Nov. 29 , p. 859 ) advises pelvic sympathectomy " in cases of endometriosis in which conservatism is advisable." I agree wholeheartedly. Indeed, I have practised this for some time, and in addition I suspend the uterus to prevent retroversion due to adhesions. But I do not think Prof. Greenhill's technique goes far enough. It should be noted that he describes his operation as "Pelvic Sympathectomy" and not "Presacral Neurectomy." But he does not completely denervate the ovaries, and since endometriosis so frequently involves the ovaries it is very important to include them. Your annotator in the same issue mentioned this point with reference to the work of O'Donel Browne (1939) in the treatment of ovarian dysmenorrhoea.

Mitchell (1938) summarizes the nerves to the ovary as follows: (a) A superior group from the intermesenteric nerves and from the renal plexus. (b) A middle or intermediate group from the superior hypogastric plexus or from the hypogastric nerve. . . It is possible that the nerve supply to the ovary may be mainly sympathetic in nature, and confined to those nerves described above as the superior and middle ovarian nerves. The inferior ovarian nerves supply filaments both to the uterus and tubes but few (if any) to the ovaries." Therefore in addition to presacral neurectomy I feel it advisable to incise the infundibulo-pelvic ligaments to complete the pelvic sympathectomy. In many cases of endometriosis this will be necessary on one side only, because pathology in the opposite ovary has already necessitated its removal.-I am, etc., Oxford.

G. Gordon LenNon.

REFERENCES

Brown, O'Donel (1939), J. Obstet. Gynaec. Brit. Emp., 46, 962. Mitchell, G. A. G. (1938). J. Anat., 72, 515.

\section{A Medico-Nurșing Society}

SIR,-It is only in recent years that the importance of postgraduate medical education has received appropriate recognition. As far as nurses are concerned, however, such education is neglected and sometimes even ignored. The problem of maintaining the interests of nurses alert and up to date is not less urgent than the similar problem in relation to doctors. When I arrived at St. Bernard's Hospital as Deputy Medical Superintendent, after several years away in the R.A.M.C., a number of senior nurses requested my help in keeping their knowledge of modern developments in psychiatry and nursing abreast of the times. I found the matter presented many difficulties, such as the fact that the majority of senior male nurses and a large number of the female ones live out of hospital, most of them being married and having family obligations. After due consideration I concluded that a mere series of lectures would not in itself suffice. I sought to devise a scheme that would attract 